\title{
Auscultatory and Phonocardiographic Manifestations of Isolated Stenosis of the Pulmonary Artery and its Branches*
}

\author{
JOSEPH K.-PERLOFF AND E. JOSEPH LEBAUER \\ From the Department of Medicine, Georgetown University School of Medicine, Division of Cardiology, \\ Georgetown University Hospital, Washington, D.C., U.S.A.
}

Stenosis of the pulmonary artery and its branches -a malformation described by Oppenheimer in 1938-is characterized by narrowing of the pulmonary trunk, its bifurcation, or its primary or peripheral branches (D'Cruz et al., 1964; Franch and Gay, 1963). Occasionally, membranous obstruction occurs just above the pulmonary valve (Franch and Gay, 1963; Arvidsson et al., 1961; Smith, 1958). Pulmonary artery stenosis may be unilateral (Luan et al., 1960) or bilateral (Agustsson et al., 1962), single or multiple (D'Cruz et al., 1964); it may involve a localized arterial site with poststenotic dilatation or varying lengths of a branch from segmental narrowing to diffuse tubular hypoplasia (D'Cruz et al., 1964; Franch and Gay, 1963). Though pulmonary artery stenosis occurs as an isolated congenital malformation, it frequently coexists with other anomalies, especially valvular pulmonary stenosis (Hall et al., 1961; Franch and Gay, 1963; D'Cruz et al., 1964; Rowe, 1963), atrial septal defect (Shafter and Bliss, 1959; Franch and Gay, 1963), ventricular septal defect (D'Cruz et al., 1964), patent ductus arteriosus (Rowe, 1963; D'Cruz et al., 1964; Venables, 1965), and Fallot's tetralogy (Baum et al., 1964; D'Cruz et al., 1964). In addition, the combination of supravalvular aortic stenosis and bilateral branch stenosis of the pulmonary arteries forms a recognizable syndrome, especially when accompanied by peculiar facies, abnormal dentition, mental retardation, and infantile hypercalcaemia (Beuren et al., 1964). Despite considerable interest in pulmonary artery stenosis, a number of its clinical features remain ill defined.

Received September 17, 1968.

* This study was supported in part by a Research Career Program Award, by a U.S. Public Health Service Grant, and by the Eric T. Paglin Memorial Fund for Cardiovascular Teaching and Research.
Accordingly, auscultatory, phonocardiographic, haemodynamic, and angiographic observations were made in 11 patients with isolated stenosis of the pulmonary artery and its branches. The resulting paper has two purposes: (1) to describe our own observations regarding the acoustic signs, with special reference to murmurs and the second heart sound, and (2) to provide a critical review of the auscultatory and phonocardiographic data published by others.

\section{SUBJECTS AND MethodS}

Observations were made on 11 patients, 7 female and 4 male, ranging in age from $2 \frac{1}{2}$ to 19 years (Table I). Seven were believed to have uncomplicated stenosis of the pulmonary artery and its branches. Four additional patients originally had coexisting congenital malformations, namely, small patent ductus arteriosus (Case 8), coarctation of the aorta (Case 9), atrial septal defect (Case 10), and mild subvalvular aortic stenosis (Case 11^). Each of these 4 patients had undergone surgical repair of the associated anomaly, leaving them with isolated pulmonary artery stenosis (Table II).

Diagnoses were initially entertained on the basis of the history, physical signs, electrocardiogram, and $x$-ray. Thoracic wall phonocardiograms were taken with a Sanborn Polybeam Photographic recorder after careful auscultation. Tracings were recorded at the cardiac apex, lower left sternal edge, second interspaces to the left and right of the sternum, and at appropriate murmur sites in the left anterior chest, right anterior chest, axillae, and back. Intracardiac phonocardiograms were recorded in three instances using a barium titanate catheter tip microphone. Diagnoses were confirmed by cardiac catheterization and angiocardiography (Fig. 1). The presence of pulmonary artery stenosis was established by: (1) careful continuous withdrawal of the catheter

* This patient represents, to the best of our knowledge, a unique example of pulmonary artery stenosis occurring with 314 subvalvular rather than supravalvular aortic stenosis. 
TABLE I

CLINICAL AND PHONOCARDIOGRAPHIC DATA

\begin{tabular}{|c|c|c|c|c|c|c|c|c|c|c|c|}
\hline \multirow{3}{*}{$\begin{array}{l}\text { Case } \\
\text { No. }\end{array}$} & \multirow{3}{*}{$\begin{array}{l}\text { Age } \\
\text { (yr.) }\end{array}$} & \multirow{3}{*}{ Sex } & \multirow{3}{*}{ Systolic murmur, grade, and site } & \multirow{3}{*}{$\begin{array}{l}\text { Cont. } \\
\text { murm. }\end{array}$} & \multirow{3}{*}{$\begin{array}{c}\text { Diast. } \\
\text { murm. }\end{array}$} & \multicolumn{3}{|c|}{ Second heart sound } & \multirow{3}{*}{$\begin{array}{l}\text { Ejec. } \\
\text { sound }\end{array}$} & \multirow{3}{*}{$\begin{array}{l}\text { Atrial } \\
\text { sound }\end{array}$} & \multirow{3}{*}{ S3 } \\
\hline & & & & & & \multirow{2}{*}{ Intensity } & \multicolumn{2}{|c|}{ Splitting } & & & \\
\hline & & & & & & & Expir. & Inspir. & & & \\
\hline 1 & $2 \frac{1}{2}$ & $\mathbf{F}$ & $\begin{array}{l}\text { Maximal grade } 3 / 6 \text { left ant. chest } 2 \text { ICS; } \\
\text { well heard (grade } 2 / 6 \text { ) in rt. chest, }\end{array}$ & No & No & A2 > P2 & 0.00 & 0.03 & No & Yes & Yes \\
\hline 2 & 4 & $\mathbf{F}$ & $\begin{array}{l}\text { Maximal grade } 3 / 6 \text { left ant. chest } 2 \text { ICS; } \\
\text { well heard (grade } 2 / 6) \mathrm{rt} \text {. chest, } \\
\text { axillae, and back }\end{array}$ & No & No & $\mathbf{A} 2=\mathbf{P} 2$ & 0.00 & 0.05 & Yes & Yes & Yes \\
\hline 3 & 6 & $\mathbf{F}$ & Grade $2 / 6$ upper left ant. chest; almost & No & No & A2 $<$ P2 & 0.00 & 0.04 & No & No & Yes \\
\hline 4 & 4 & $\mathbf{F}$ & $\begin{array}{l}\text { Maximal grade } 3 / 6 \text { upper left chest; } \\
\text { almost equal rt. chest, axillae, and back }\end{array}$ & No & No & $\mathbf{A} 2=\mathbf{P} 2$ & 0.00 & 0.04 & No & No & No \\
\hline 5 & 6 & $\mathbf{M}$ & $\begin{array}{l}\text { Maximal grade } 3 / 6 \text { left ant. chest } 2 \text { and } \\
3 \text { ICS; almost equal in rt. chest; }\end{array}$ & No & No & $\mathbf{A} 2=\mathbf{P 2}$ & 0.01 & 0.05 & No & No & Yes \\
\hline 6 & 19 & $\mathbf{M}$ & $\begin{array}{l}\text { Maximal grade } 3 / 6 \text { in rt. and left ant. } \\
\text { upper chest; almost equal in axillae }\end{array}$ & No & No & A2 > P2 & 0.02 & 0.06 & No & No & No \\
\hline 7 & 5 & $\mathbf{F}$ & $\begin{array}{l}\text { Grade } 3 / 6 \text {, almost equal in left and right } \\
\text { ant. chest, axillae, and back }\end{array}$ & No & No & A2 $>$ P2 & 0.02 & 0.04 & No & No & Yes \\
\hline $8^{\star}$ & 6 & $\mathbf{F}$ & $\begin{array}{l}\text { Maximal grade } 2 / 6 \text { left ant. chest } 2 \text { and } \\
3 \text { ICS; slightly less in axillae and back }\end{array}$ & No & Yes & $\mathbf{A} 2>\mathbf{P 2}$ & 0.00 & 0.04 & No & No & Yes \\
\hline $9 \dagger$ & 4 & $\mathbf{F}$ & Maximal grade $3 / 6$ left ant. upper chest; & No & No & $\mathbf{A 2}>\mathbf{P} 2$ & 0.00 & 0.04 & No & No & Yes \\
\hline $10 \ddagger$ & 5 & $\mathbf{M}$ & $\begin{array}{l}\text { Maximal grade } 3 / 6 \text { upper right ant. chest; } \\
\text { almost equal in left chest, axil., and back }\end{array}$ & No & No & A2 > P2 & 0.00 & 0.04 & No & Yes & Yes \\
\hline $11 \S$ & 9 & $\mathbf{M}$ & $\begin{array}{l}\text { Max. grade } 3 / 6 \text { upper ant. chest, right } \\
\text { slightly greater than left; grade } 2 / 6- \\
\text { axillae and back }\end{array}$ & No & No & $\mathbf{A 2}>\mathbf{P} 2$ & 0.00 & 0.04 & No & Yes & Yes \\
\hline
\end{tabular}

ICS = Intercostal space.

^ Post-operative patent ductus.

+ Post-operative coarctation of the aorta.

from the peripheral branches of both right and left pulmonary arteries into the right ventricle, (2) inspection of the contour of the pressure pulse recorded from the proximal pulmonary trunk (Agustsson et al., 1962), and (3) selective pulmonary angiocardiography (Arvidsson, Karnell, and Möller, 1955). Intracardiac shunts were excluded by indicator dilution curves and by krypton- 85 inhalation. Aortic stenosis was sought by entering the left ventricle, by inspecting the laevophase of the angiocardiograms, or by selective aortography.

\section{RESULTS}

Haemodynamic and angiocardiographic data are summarized in Table II. Severity of pulmonary artery stenosis ranged from mild to marked. The sites of obstruction were identified in the angiocardiograms, in addition to which careful note was made of the fluoroscopic location of the catheter tip when a gradient was recorded. All 11 patients had 


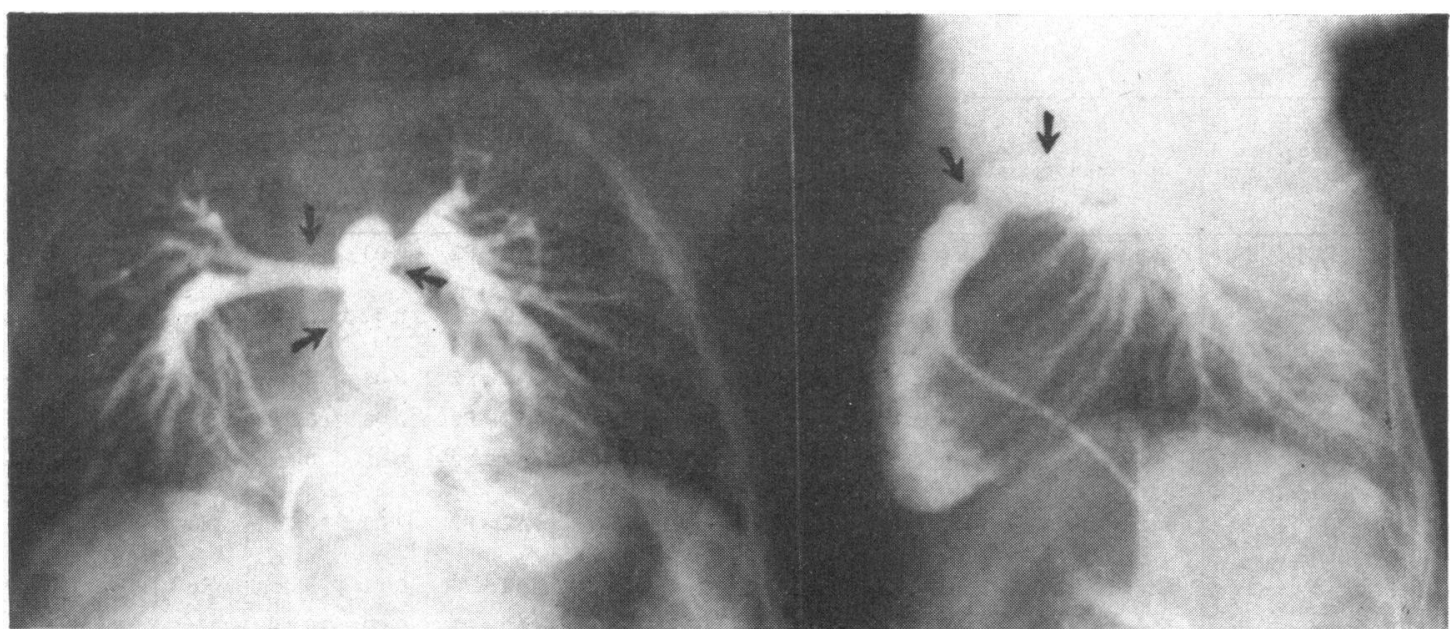

FIG. 1.-Angiocardiogram in Case 1, a $2 \frac{1}{2}$-year-old girl. Contrast material was injected into the outflow tract of the right ventricle. In the frontal view, the lower left arrow identifies the pulmonary valve, the upper left arrow points to tubular hypoplasia of the right pulmonary artery, and the arrow on the right localizes a zone of stenosis in the pulmonary trunk. The intrapulmonary vessels in both lungs exhibit post-stenotic dilatation. In the lateral view, the arrow on the left identifies the segment of stenosis in the pulmonary trunk, and the second arrow points to an abrupt constriction at the bifurcation.

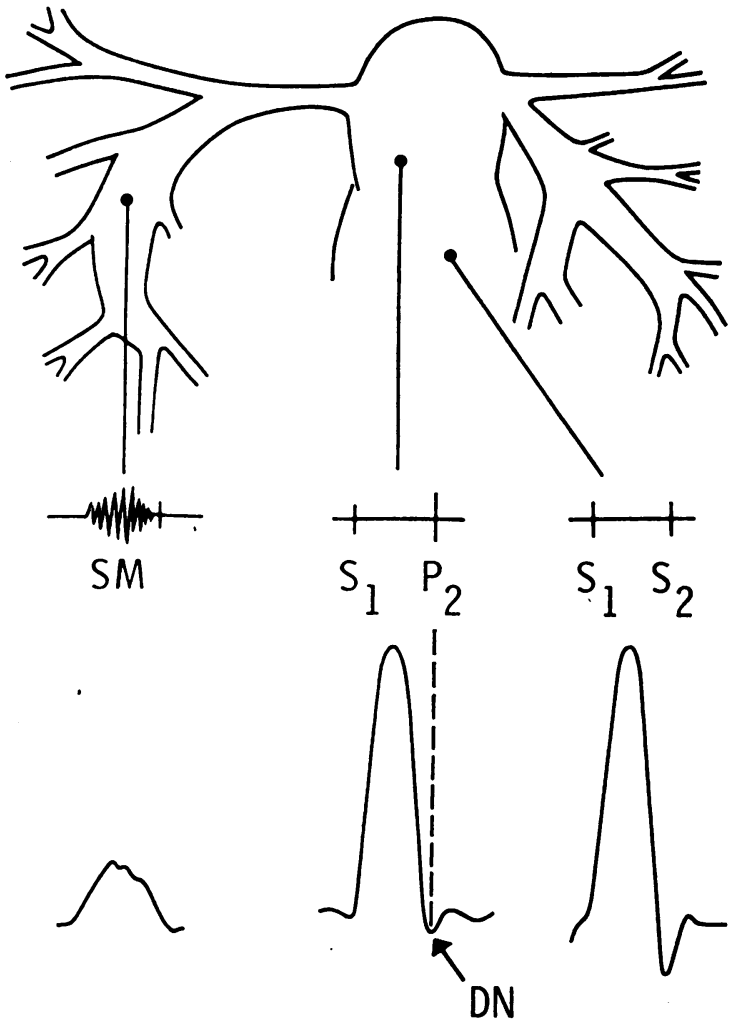

DISTAL PA MAIN PA RV stenoses in the proximal (extrapulmonary) portions of the pulmonary arterial tree, i.e. in the pulmonary trunk, at the bifurcation, or in the right and left main branches. Two patients (Cases 2 and 10) had multiple sites of distal (intrapulmonary) stenoses as well.

The central pulmonary arterial pressure pulse showed the characteristic contour of bilateral branch stenosis (Agustsson et al., 1962) (Fig. 2). The systolic peak fell rapidly to a low dicrotic notch so the valve closed at pressures that were normal or nearly so. The diastolic pressures that were recorded proximal and distal to the sites of obstruction were virtually identical, so that gradients were systolic and not diastolic.

Intracardiac phonocardiograms (Cases 4, 6, and 9) recorded crescendo-decrescendo systolic murmurs distal to the zones of stenosis (Fig. 3). These murmurs were recorded just beyond the most proximal site of obstruction and were well recorded in distal branches whether or not additional zones

FIG. 2.-Composite of anatomical, intracardiac phonocardiographic, and haemodynamic features of pulmonary artery stenosis. A systolic murmur is inscribed in the distal pulmonary artery upstream from the arterial constriction. The pressure pulse in the main pulmonary artery is typical of bilateral pulmonary artery stenosis with a brisk rise and a rapid fall to a low dicrotic notch (DN). The gradient is systolic and not diastolic so the murmur is confined to systole. The pulmonary closure sound $\left(\mathrm{P}_{2}\right)$ is not increased since the valve shuts at a relatively low pressure (DN). 


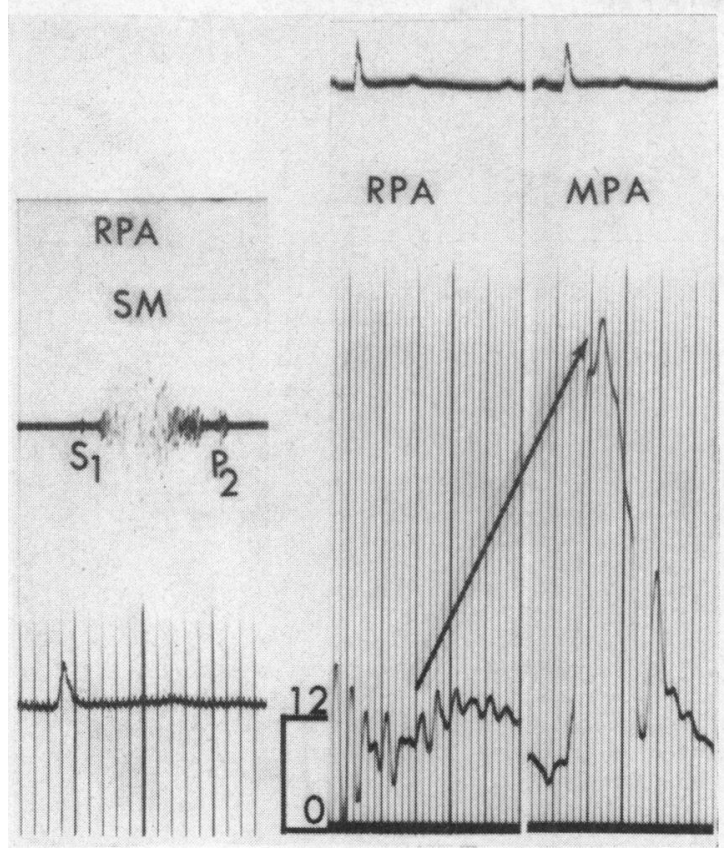

FIG. 3.-Intracardiac phonocardiogram and pressure pulses from right pulmonary artery (RPA) and main pulmonary artery (MPA) in Case 6, a 19-year-old man. A crescendodecrescendo systolic murmur is recovered in the RPA distal to the zone of stenosis. The gradient from RPA to MPA is systolic and not diastolic, so the murmur is confined to systole. The MPA pressure pulse exhibits the typical contour of bilateral pulmonary artery stenosis. The pulmonary closure sound is not increased despite pulmonary hypertension, because the valve closes at a pressure of $10 \mathrm{~mm}$. $\mathrm{Hg}$.

of stenosis were present. When the microphone was withdrawn, the murmur abruptly faded as the catheter tip traversed the obstruction and entered the high pressure area.

Amyl nitrite inhalation (Cases 8 and 9) resulted in an increase in the intensity of the systolic murmur in both instances (Fig. 4) and caused a significant increase in the gradient in Case 9 but not in Case 8.

Data derived from auscultation and chest wall phonocardiography are summarized in Table $I$. Murmurs exhibited their maximum intensities in the upper anterior chest and were generally greater to the left of the sternum. The chest wall location appeared to be related to the sites of obstruction in the proximal (extrapulmonary) portions of the pulmonary artery. Widespread thoracic distribution resulted from: (1) peripheral (intrapulmonary) transmission from these proximal sites, and (2) origin in stenosed intrapulmonary branches (Cases 2 and 10). In Case 9, widely distributed thoracic systolic murmurs were well recorded in the first

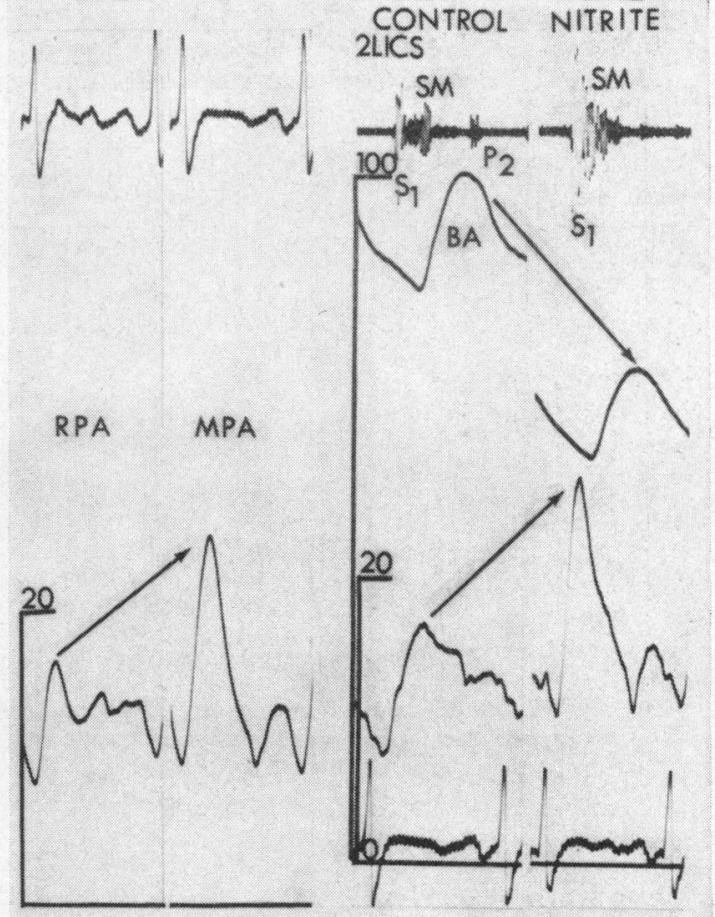

Fig. 4.-Pressure pulses and phonocardiograms before and after amyl nitrite inhalation in Case 8, a 6-year-old girl. The first two panels show the changes in height and contour of the pressure pulses from RPA to MPA. The third panel contains the control phonocardiogram with BA and RPA pressure pulses. After nitrite inhalation (fourth panel), the systolic murmur (SM) increased and the BA pressure fell, though the gradient (arrow) remained essentially unchanged. 2 LICSsecond left intercostal space; BA-brachial artery.

year of life at an age when the collateral circulation of coarctation of the aorta is rarely sufficient to account for such murmurs. These murmurs were unchanged two years after resection of the coarctation. In Case 11, the systolic murmur remained slightly greater in the right anterior upper chest, even after surgical resection of a subaortic fibrous obstruction had abolished the left ventricularaortic gradient. In Case 8, a low frequency, soft diastolic murmur was recorded in the mid-left anterior chest. The pulmonary arteriogram showed no evidence of pulmonary regurgitation. A small diastolic gradient existed across the site of stenosis and may have accounted for this murmur. Continuous murmurs were carefully sought but not detected.

The intensity of the pulmonary closure sound was equal to or less than the sound of aortic closure when both were recorded simultaneously in the second left interspace (Fig. 5). In Case 3, pulmonary closure exceeded aortic closure in loudness but only 


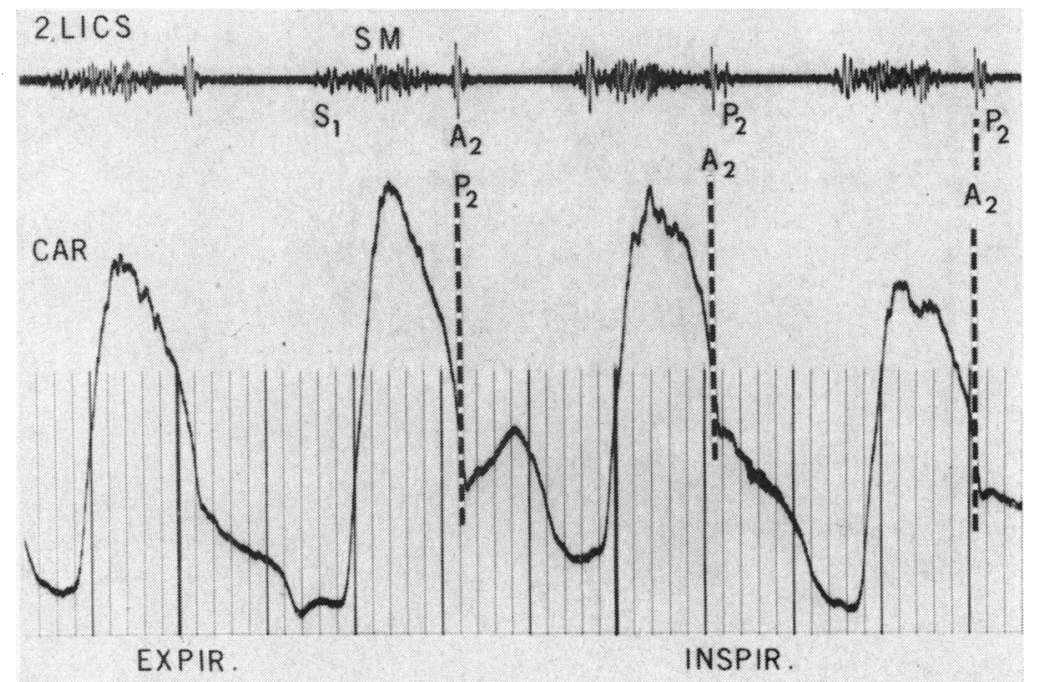

Fig. 5.-Phonocardiogram and carotid arterial pulse from Case 10, a 5-year-old boy. A relatively long crescendo-decrescendo systolic murmur (grade $3 / 6$ ) is recorded in the second left intercostal space. During inspiration, the second sound splits into aortic $\left(\mathbf{A}_{2}\right)$ and pulmonary $\left(\mathbf{P}_{2}\right)$ components. The latter component $\left(P_{2}\right)$ is neither increased nor delayed.

slightly so (normal range). The degree of expiratory splitting was 0.00 to 0.02 sec., and the degree of inspiratory splitting was 0.03 to 0.06 sec., i.e. within normal range (Table I). When splitting persisted during expiration, re-examination in the sitting position was usually normal.

A pulmonary ejection sound was heard and recorded in Case 2, a 4-year-old girl with moderate to severe obstruction at the origins of the right and left pulmonary arterial branches. The pulmonary trunk was slightly dilated but the valve appeared normal.

The atrial sounds in Cases $1,2,10$, and 11 could be accounted for by the increased force of right atrial contraction analogous to that found in other forms of right ventricular hypertension. The incidence of third heart sounds was appropriate for the age-group.

\section{Discussion}

Murmurs associated with isolated stenosis of the pulmonary artery and its branches are usually systolic (Fig. 2, 3, and 5) and only occasionally continuous. Earlier impressions regarding the incidence of continuous murmurs have not been borne out by subsequent observations (Franch and Gay, 1963; D'Cruz et al., 1964). The distribution of systolic murmurs is influenced by the location of the stenotic areas. Since these sites of obstruction are usually multiple (Fig. 1) and involve the main pulmonary artery as well as the proximal and distal branches, it is understandable that the systolic murmur is characterized by a wide thoracic distribution (Venables, 1965; D'Cruz et al., 1964; Delaney and Nadas, 1964; Franch and Gay, 1963). Accordingly, systolic murmurs are not only heard centrally in the vicinity of the second left and right interspaces but also peripherally in the axillae and back (Luan et al., 1960; Venables, 1965; Franch and Gay, 1963; Shafter and Bliss, 1959). Murmur in the vicinity of the second right interspace may be difficult to distinguish from supravalvular aortic stenosis which in fact may coexist (Beuren et al., 1964). A lower left sternal edge murmur may superficially resemble ventricular septal defect because of the location but not the configuration. It is important to emphasize that interpretation of these thoracic murmurs requires a judgment as to whether they originate peripherally or whether they merely radiate from a loud anterior murmur. This distinction can usually be made when pulmonary artery stenosis occurs as an uncomplicated lesion, but may be impossible when it coexists with malformations that generate loud praecordial murmurs such as valvular pulmonary stenosis, ventricular septal defect, or patent ductus. Furthermore, peripheral pulmonary murmurs can occur in the presence of uncomplicated atrial septal defects with large shunts and hyperkinetic pulmonary flows (Perloff, Caulfield, and de Leon, 1967). Under these circumstances it may be difficult to distinguish 
peripheral murmurs due to flow alone from those due to coexisting stenosis of the pulmonary artery or its branches.

Systolic murmurs of pulmonary artery stenosis are typically crescendo-decrescendo in configuration (Fig. 2, 3, and 5). Onset after the first heart sound may be slightly delayed owing to the relatively distal origin of the murmur. The zone of stenosis often begins at or near the bifurcation of the pulmonary trunk; accordingly, the basal murmur, especially the one in the region of the second left interspace, is usually the most prominent (Arvidsson et al., 1961) (Fig. 5) and may occasionally reach grade $4 / 6$. As a rule, however, the anterior murmur is grade $3 / 6$ (D'Cruz et al., 1964) and the peripheral murmur equal or nearly so (Table I). The very fact that peripheral and praecordial murmurs are nearly equal in intensity supports the conclusion that wide thoracic distribution is not simply the result of a loud anterior murmur. Amyl nitrite tends to increase the loudness of these systolic murmurs by increasing the flow rate across the stenotic segments (Fig. 4). Intracardiac phonocardiograms show that systolic murmurs can originate in the vicinity of the bifurcation and main pulmonary arterial branches, and then propagate distally into peripheral branches that are not stenotic (Fig. 3). This observation appears to account for both the location of the anterior murmur as well as the widespread distribution in axillae and back. Additional areas of distal (intrapulmonary) stenosis may result in randomly localized sites of louder peripheral murmurs.

Continuous murmurs may occur in pulmonary artery stenosis (Eldridge, Selzer, and Hultgren, 1957; Arvidsson et al., 1961; Shafter and Bliss, 1959; Baum et al., 1964; Luan et al., 1960; Vermillion, Leight, and Davis, 1958; Gyllenswärd et al., 1957; Franch and Gay, 1963), and depending upon their location, may lead to a mistaken diagnosis of patent ductus arteriosus (Arvidsson et al., 1961; Gyllenswärd et al., 1957). The association of these two anomalies, especially in the rubella syndrome, must be kept in mind (Venables, 1965). However, in uncomplicated stenosis of the pulmonary artery and its branches, a systolic murmur is the rule and a continuous murmur the exception. The following mechanisms appear to account for this (Fig. 2). Continuous murmurs imply continuous gradients across the sites of stenosis (Eldridge et al., 1957). Observations of the pressure pulses proximal and distal to the zones of obstruction show that continuous gradients are not the rule. The central pulmonary artery pulse is characterized by a raised systolic pressure but a rapid fall to a diastolic level that is normal or nearly so (Agustsson et al., 1962) (Fig. 2). The gradient across the stenotic site is generally systolic and not diastolic, so that the murmur occurs in systole and does not continue into diastole (Luan et al., 1960) (Fig. 2). Why then do continuous murmurs occur at all ? It has been postulated that systolic expansion of the high pressure proximal pulmonary artery sets the stage for brisk diastolic flow across the stenotic segment as the expanded proximal vessels relax (Gyllenswärd et al., 1957; Eldridge et al., 1957). Furthermore, gradients occasionally persist into diastole (Eldridge et al., 1957). The foregoing comments assume that continuous murmurs originate at the sites of stenosis, an assumption that need not be so. Pulmonary arterial obstruction may lead to an increase in the amount of blood flow through bronchial collateral arteries (Liebow et al., 1950; Falkenbach et al., 1959). Bronchial collateral circulation is a wellknown source of continuous murmurs (Campbell and Deuchar, 1961). In one study of pulmonary artery stenosis, a continuous murmur was believed to originate in bronchial arteries that were clearly demonstrated by selective angiocardiography (Lees and Dotter, 1965). If the continuous murmur originates in a bronchial artery, amyl nitrite inhalation might decrease its loudness by decreasing the systemic arterial pressure. If the continuous murmur originates in a stenotic pulmonary artery, amyl nitrite should increase its loudness (Fig. 4) by increasing the rate of flow across the site of obstruction.

A modest diastolic gradient may exist at the zone of stenosis despite the precipitous fall in pulmonary arterial pressure to a relatively low level. A large systolic gradient followed by a comparatively small diastolic gradient may account for the occasional occurrence of a prominent systolic murmur followed by a soft low-pitched murmur in diastole (Shafter and Bliss, 1959) (Case 8).

The high frequency murmur of pulmonary incompetence has not been specifically described, though in one case there was an early diastolic blowing murmur in the second left interspace (Delaney and Nadas, 1964). Graham Steell murmurs are unlikely, despite considerable pulmonary hypertension. This is so because the pressure exerted against the pulmonary valve during diastole is relatively low and because the pulmonary trunk is usually not dilated.

Analysis of both the intensity and splitting of the second heart sound is important in the auscultatory assessment of the various forms of isolated pulmonary stenosis. It is commonly assumed that pulmonary stenosis causes wide splitting of the second heart sound (Leatham and Weitzman, 1957) and pulmonary hypertension increases the intensity of its second component (Perloff, 1967). Factors 
that influence the second heart sound in pulmonary artery stenosis differ from those that affect the second sound in valvular or subvalvular obstruction. When the stenotic sites are upstream from the valve, the pressure in the pulmonary trunk is increased, not reduced (Fig. 2). However, pulmonary artery stenosis is unique among causes of pulmonary hypertension since it raises the systolic but not the diastolic pressure (Agustsson et al., 1962) (Fig. 2 and 5) and the pulmonary valve closes at a normal or nearly normal pressure (Perloff, 1967). The pulmonary closure sound should therefore be normal in amplitude (Fig. 5), provided that its intensity is a function of the pressure at which the valve shuts. On the other hand, the cusps appear to bulge more rapidly than normal toward the right ventricular cavity during isometric relaxation, suddenly increasing the volume capacity of the pulmonary trunk (Agustsson et al., 1962). If the intensity of pulmonary closure were influenced by the abruptness with which the leaflets seat, then the resulting sound should be increased. Though some observers have described a relatively loud pulmonary component of the second heart sound (Delaney and Nadas, 1964; Gyllenswärd et al., 1957), others have not found a uniform increase in intensity (Perloff, 1967; Venables, 1965; Franch and Gay, 1963; D'Cruz et al., 1964; Arvidsson et al., 1961; Bourassa and Campeau, 1963; Dighiero et al., 1957). In any event, in valvular or subvalvular pulmonary stenosis, the loudness of pulmonary closure usually varies inversely with the degree of obstruction (Perloff, 1963), whereas in pulmonary artery stenosis, the intensity is maintained but not necessarily increased as the obstruction becomes more severe.

In stenosis of the pulmonary artery and its branches, a potential increase in the duration of ejection may be cancelled by the rapidity with which the pulmonary artery pressure falls from its systolic peak (Agustsson et al., 1962) (Fig. 2 and 3). The timing of pulmonary closure should, therefore, not be judged by criteria that apply to valvular or subvalvular stenosis in which the duration of right ventricular ejection is characteristically prolonged (Leatham and Weitzman, 1957). In isolated pulmonary artery stenosis, the second heart sound may be narrowly split (Fig. 5), even in the face of appreciable obstruction (Delaney and Nadas, 1964; Venables, 1965; Perloff, 1967). It is usually found that the degree of splitting varies appropriately with respiration (Perloff, 1967) (Fig. 5). Wide or persistent splitting of the second heart sound should therefore be taken as evidence of coexisting valvular pulmonary stenosis or atrial septal defect.

The foregoing comments do not imply that stenosis of the pulmonary artery and its branches invariably leaves the pulmonary closure sound normal in timing and intensity. However, the observations do indicate that despite appreciable stenosis and significant pulmonary hypertension, the peculiar physiology of the trunk pressure may allow the valve to close with a relatively normal intensity and with little or no delay.

\section{SUMMARY}

Despite considerable interest in pulmonary artery stenosis, some of its clinical features have been ill defined. Because of this, auscultatory, phonocardiographic, haemodynamic, and angiographic observations were made in a group of patients with isolated stenosis of the pulmonary artery and its branches. Particular attention was paid to the murmurs and to certain previously undescribed points regarding the second heart sound. Proximal pulmonary arterial pressure pulses showed systolic hypertension with rapid falls to diastolic levels found in distal sites. Arterial gradients were therefore systolic and not diastolic and the accompanying murmurs were systolic and not continuous. The intensity of pulmonary closure was normal since pulmonary artery stenosis raised the systolic but not the diastolic pressures, and the valve closed at approximately normal pressures. Rapid bulging of the cusps toward the ventricle during isometric relaxation did not seem to augment the pulmonary closure sound. Pulmonary closure was not delayed (normal splitting) because the potential increase in duration of right ventricular ejection due to the stenosis was cancelled by the rapid fall in pulmonary arterial pressure (elastic recoil) after its systolic peak.

\section{REFERENCES}

Agustsson, M. H., Arcilla, R. A., Gasul, B. M., Bicoff, J. P., Nassif, S. I., and Lendrum, B. L. (1962). The diagnosis of bilateral stenosis of the primary pulmonary artery branches based on characteristic pulmonary trunk pressure curves. Circulation, 26, 421.

Arvidsson, H., Carlsson, E., Hartmann, A., Tsifutis, A., and Crawford, C. (1961). Supravalvular stenoses of the pulmonary arteries. Acta radiol. (Stockh.), 56, 466.

—, Karnell, J., and Möller, T. (1955). Multiple stenosis of the pulmonary arteries associated with pulmonary hypertension, diagnosed by selective angiocardiography. Acta radiol. (Stockh.), 44, 209.

Baum, D., Khoury, G. H., Ongley, P. A., Swan, H. J. C., and Kincaid, O. W. (1964). Congenital stenosis of the pulmonary artery branches. Circulation, 29, 680.

Beuren, A. J., Schulze, C., Eberle, P., Harmjanz, D., and Apitz, J. (1964). The syndrome of supravalvular aortic stenosis, peripheral pulmonary stenosis, mental retardation and similar facial appearance. Amer. F. Cardiol., 13, 471 .

Bourassa, M. G., and Campeau, L. (1963). Combined supravalvular aortic and pulmonic stenosis. Circulation, 28, 572. 
Campbell, M., and Deuchar, D. C. (1961). Continuous murmurs in cyanotic congenital heart disease. Brit. Heart F., 23, 173.

D'Cruz, I. A., Agustsson, M. H., Bicoff, J. P., Weinberg, M., and Arcilla, R. A. (1964). Stenotic lesions of the pulmonary arteries. Amer. F. Cardiol., 13, 441.

Delaney, T. B., and Nadas, A. S. (1964). Peripheral pulmonic stenosis. Amer. F. Cardiol., 13, 451.

Dighiero, J., Fiandra, O., Barcia, A., Cortés, R., and Stanham, J. (1957). Multiple pulmonary stenoses with pulmonary hypertension. Acta radiol. (Stockh.), 48, 439.

Eldridge, F., Selzer, A., and Hultgren, H. (1957). Stenosis of a branch of the pulmonary artery, an additional cause of continuous murmurs over the chest. Circulation, 15, 865 .

Falkenbach, K. H., Zheutlin, N., Dowdy, A. H., and O'Loughlin, B. J. (1959). Pulmonary hypertension due to pulmonary arterial coarctation. Radiology, 73, 575.

Franch, R. H., and Gay, B. B. (1963). Congenital stenosis of the pulmonary artery branches. Amer.F. Med., 35, 512 .

Gyllenswärd, A., Lodin, H., Lundberg, A., and Möller, T. (1957). Congenital, multiple peripheral stenoses of the pulmonary artery. Pediatrics, 19, 399.

Hall, P., Johansson, B. W., Krook, H., Malm, A., Olsson, N., Andrén, L., and Wulff, H. (1961). Coarctation of the pulmonary artery and pulmonary valvular stenosis. Amer. F. Cardiol., 8, 109.

Leatham, A., and Weitzman, D. (1957). Auscultatory and phonocardiographic signs of pulmonary stenosis. Brit. Heart f., 19, 303.

Lees, M. H., and Dotter, C. T. (1965). Bronchial circulation in severe multiple peripheral pulmonary artery stenosis. Circulation, 31, 759.
Liebow, A. A., Hales, M. R., Bloomer, W. E., Harrison, W., and Lindskog, G. E. (1950). Studies on the lung after ligation of the pulmonary artery. Amer. F. Path., 26, 177.

Luan, L. L., D'Silva, J. L., Gasul, B. M., and Dillon, R. F. (1960). Stenosis of the right main pulmonary artery. Circulation, 21, 1116.

Oppenheimer, E. H. (1938). Partial atresia of the main branches of the pulmonary artery occurring in infancy and accompanied by calcification of the pulmonary artery and aorta. Bull. Fohns Hopk. Hosp., 63, 261.

Perloff, J. K. (1963). Recognition and differential diagnosis of pulmonary stenosis. In The Theory and Practice of Auscultation, p. 216. Ed. by B. L. Segal. F. A. Davis, Philadelphia.

- (1967). Auscultatory and phonocardiographic manifestations of pulmonary hypertension. Progr. cardiovasc. Dis., 9, 303.

—, Caulfield, W. H., and de Leon, A. C. (1967). Peripheral pulmonary artery murmur of atrial septal defect. Brit. Heart f., 29, 411.

Rowe, R. D. (1963). Maternal rubella and pulmonary artery stenoses: Report of 11 cases. Pediatrics, 32, 180.

Shafter, H. A., and Bliss, H. A. (1959). Pulmonary artery stenosis. Amer. F. Med., 26, 517.

Smith, W. G. (1958). Pulmonary hypertension and a continuous murmur due to multiple peripheral stenoses of the pulmonary arteries. Thorax, 13, 194.

Venables, A. W. (1965). The syndrome of pulmonary stenosis complicating maternal rubella. Brit. Heart f., 27, 49.

Vermillion, M. B., Leight, L., and Davis, L. A. (1958). Pulmonary artery stenosis. Circulation, 17, 55. 